\title{
ToDIGRA Diversity Workshop Special Issue Introduction
}

Sian Beavers \& Darshana Jayemanne

Transactions of the Digital Games Research Association August 2018, Vol 4 No 1, pp i-xv

ISSN 2328-9422

(C) The text of this work is licensed under a Creative Commons Attribution -- NonCommercial --NonDerivative 4.0 License (http://creativecommons.org/licenses/by-nc-nd/ 2.5/).

IMAGES: All images appearing in this work are property of the respective copyright owners, and are not released into the Creative Commons. The respective owners reserve all rights.

The inaugural DiGRA Diversity Workshop, “Gaming the System”, was held at The University of Melbourne on 2ndJuly 2017; we thank and acknowledge the Wurundjeri people as Traditional Custodians of this land. The Workshop was an initiative of the Diversity Working Group that first met in 2015. The event drew together five formal papers (four of which have proceeded to peer review and appear in this special issue) followed by a general discussion. The aim of the Workshop was to critically interrogate what it would mean for Game Studies to be diverse, and to invite presentations that could expand our ideas about diversity. This included questioning whether 'diversity' is an unalloyed good, the nature of the non-diverse 'norm' from which it putatively offers 
a departure, and the function of diversity as a discourse operative within the contemporary academy.

Following the papers, the group engaged in a facilitated discussion forum. The opening discussion concerned the significant diversity initiatives that had been put in place by the organisers of the 2017 conference, which it was hoped would be exemplary for future committees. These included sliding-scale pricing for delegates from different Socio-Economic Status (SES) countries, diversityoriented breakfasts and dinners, and a robust Twitter/social media policy enabling delegates to be proactive about their representation online.

Following this, broader discussions about diversity and DiGRA arose. While the discussion covered a wide range of topics, a few key themes arose. These themes are presented, along with open questions for consideration:

- What are the regional issues that impend on diversity, and how can they best be addressed? Would a one-sizefits-all approach lead to problems in certain cases? How can the DiGRA board, the DiGRA Diversity Group and regional chapters best work together? How do regions without DiGRA chapters relate to the organisation, and are there cases in which working to establish local chapters would be beneficial, irrelevant or counterproductive?

- When considering funding, scholarship or sliding scales for fees, what models exist, and which would be best for DiGRA to learn from? For example, the International Communications Association tends to approach its policy for financial assistance with reference to the delegate's country of origin, whereas the American Studies Association uses self-reported income. While there can be considerable income disparity within a single nation, it could be argued that official data on SES provide important structural advantages. Are there 
additional administrative overheads that come with selfreported income, how are regional living costs applicable, and what are the criteria for assistance? What mechanisms can be put in place to evaluate these questions annually?

- What are issues of accessibility that affect DiGRA delegates, and how should they influence venue selection and setup? What are the best strategies for including scholars of different ability? Are hearing loops and visual aids clearly available? If there are printed materials or signage, are they framed appropriately, and do they utilise large print with sufficient contrast? What bathroom facilities are available?

- How does jargon and insular knowledge work within the conference? The inherent interdisciplinarity of game studies, in terms of diversity, is most often a strength. However, it can also produce barriers, as it means that academics can be speaking at cross-purposes based on differing epistemological groundings and assumptions.Furthermore, game scholars can often bring up key figures, notions and quotations on the assumption that all delegates are familiar with the history of the field. This can alienate people attending their first DiGRA, or delegates from different disciplines, so there could be a case for a glossary of commonly mentioned terms and ideas. However, who would write this? What would qualify as 'common sense' in this case?

- What structures can be put in place to help those unable to attend the conference? What are the options for recording or streaming talks, and what steps can be taken to ensure that these online elements are protected from abuse? Would presenters be open to this type of online engagement, or would concerns surrounding 
potential abuse cause them misgivings about submitting to the conference? These questions would need to be carefully considered beforehand, perhaps limiting participation to registered delegates, or using an institutional login system.

- Can organising family-friendly events be part of the spirit of play that brings us together? Childcare should be a key consideration for organising committees. The responsibility of childcare often falls disproportionately on women. Although this is slowly changing, ensuring that these facilities are available may help to increase participation, not only from women, but also from delegates for whom the difficulty/cost of externallysourcing childcare is an obstacle to attending the conference.

- What are the community standards for the conference, how are they codified and disseminated? As a membership organisation, DiGRA can be quite robust with its statements about what sort of conference it wants, however, how are these statements enforced? What are the procedures for ensuring a safe space for delegates? Should proposals to host DiGRA have a requirement for local organisers to consider relevant laws that may help to ensure a safe space? Should there be a mechanism for a block-list, and if so, who would administer this? Might such a structure place the burden for dealing with an issue on a harassed person? What is to prevent any formal set of rules from being used in perverse ways?

- Can panel chairs be used more formally in facilitating diverse participation? Would it be useful to have chairs assembled at the start of the conference and trained up in issues including local resources (such as mental health hotlines), the conference's social media policy, equitably adjudicating presentation length and question 
times, and so on? Given that delegates will arrive at the conference at different times, perhaps an online training format would be more appropriate? Similarly, can - and should - DiGRA provide guidelines for selecting a panel to ensure diverse perspectives and voices, and to avoid homogeneity of nationality, gender and race?

- Time. In an age of workload allocations, unpaid peerreview that benefits incredibly profitable companies, an ever-growing academic precariat, and attention economies which favour historically cultivated privileges, what other possibilities are lost to those who devote time to 'diversity'?

Overall, the Workshop saw a robust exchange of ideas by combining formal papers with facilitated discussion, and a solid foundation was made in addressing some extremely complex issues. Perhaps the most critical insight was the need for custodianship of diversity insights, issues and approaches that can ensure transmission between conference committees and the Board.

The peer-reviewed papers assembled in this issue address the problems of diversity in games in a wider set of contexts than the DiGRA conference and organisation. The papers also favoured methodological diversity as they went through the peer-review process.

Johnstone and Pelletier present an ethnographic study of codebar London, a chapter of a non-profit organisation devoted to increasing diverse representation in technology fields through pedagogy. Johnstone and Pelletier's ethnography also informs theoretical propositions concerning 'what a feminist and critical pedagogy might look like in the tech sector', in order to treat diversity work as 'essentially political' and flag the need for more longitudinal research in this space. 
To, McDonald, Holmes, Kaufman and Hammer bring a critical eye to the diversity and character representation in contemporary games through several design techniques. Through a close analysis of exemplary games (both digital and analogue), To et al. construct a series of four recommendations for diversity in character design. Taken together, this framework advances the need for an 'end-toend process' of character design that addresses diversity across audience, production and distribution registers.

Butt, de Wildt, Kowert and Sandovar write up the results of a diversity survey conducted on the DiGRA Gamesnetwork mailing list, one of the most active communication forums for game studies scholars. While this methodology had limitations as a statistical measure of DiGRA as a complete organisation, the authors expand from purely statistical inferential methods to incorporate feminist theories of inclusivity and embodiment to frame recommendations for the continuing diversification of DiGRA and its conferences.

In our fourth paper, Wirman reports on the diversity of those DiGRA conferences, with insights gained both from her service as DiGRA Chapter Officer, president of Chinese DiGRA, and a survey of primary contacts at each DiGRA regional chapter in 2017. This discussion brings into focus issues of language, culture, community, politics and the relation of knowledge production to industry in various contexts around the globe: 'The future challenge of DiGRA as an international organisation is... in how it deals with regional diversification and whether it becomes a project of colonisation or decolonisation'.

The first DiGRA Diversity Workshop and this special issue acknowledge and diversify Wirman's statement across many registers. Asking the question of 'diversity' does not lead to a set of boxes to be checked or a formula to apply, but to the difficult terrain of a mutual ethical commitment. It is our hope that the papers herein will bring some of the debates raised at the Workshop to a greater audience and readership. It is only through facilitating an awareness of these issues that we can begin to 
ToDiGRA $x v$

instigate necessary discussions about the nature of diversity, and the implementation of diversity initiatives, both within DiGRA and Game Studies more broadly. 